\title{
Reproductive investment in Atlantic cod populations off Newfoundland: Contrasting trends between males and females
}

\author{
Loïc Baulier ${ }^{a b \dagger}$, M. Joanne Morgan ${ }^{c}$, George R. Lillyc, Ulf Dieckmann ${ }^{\text {d }}$, and Mikko Heino ${ }^{\text {abde }}$ \\ ${ }^{a}$ Institute of Marine Research, Nordnes, N-5817 Bergen, Norway; ${ }^{b}$ Department of Biology, University of \\ Bergen, N-5020 Bergen, Norway; ${ }^{c}$ Fisheries and Oceans Canada, Northwest Atlantic Fisheries Centre, \\ St. John's, NL AIC 5X1, Canada; ${ }^{\mathrm{d} E v o l u t i o n}$ and Ecology Program, International Institute for Applied \\ Systems Analysis, A-2361 Laxenburg, Austria; ${ }^{\mathrm{e}}$ Institute of Oceanography, National Taiwan University, \\ Taipei 106, Taiwan \\ *loic.baulier@ifremer.fr \\ ${ }^{\dagger}$ Present address: Ifremer, Fisheries Biodiversity Unit, UMSR LEEISA, BP 477, 97331 Cayenne, France.
}

\section{OPEN ACCESS}

Citation: Baulier L, Morgan MJ, Lilly GR, Dieckmann U, and Heino M. 2017. Reproductive investment in Atlantic cod populations off Newfoundland: Contrasting trends between males and females. FACETS 2: 660-681. doi: 0.1139 / facets-2017-0005

Editor: Kristi M. Miller

Received: January 16, 2017

Accepted: June 14, 2017

Published: August 31, 2017

Copyright: (C) 2017 Baulier et al. This work is licensed under a Creative Commons

Attribution 4.0 International License (CC BY 4.0), which permits unrestricted use, distribution, and reproduction in any medium, provided the original author(s) and source are credited.

Published by: Canadian Science Publishing

\section{Abstract}

Life history theory predicts selection for higher reproductive investment in response to increased mortality among mature individuals. We tested this prediction over the period from 1978 to 2013 for three populations of Atlantic cod (Gadus morhua) off Newfoundland. These populations were heavily fished for a long period. We considered changes in standardized gonad weight as a proxy for changes in gonadal investment. We accounted for the allometry between gonad and body weight, individual body condition, water temperature, and potential spatial and density-dependent effects. Males display significant temporal trends in gonadal investment in all populations; in agreement with theoretical predictions, these trends show increased gonadal investments during the earlier part of the time series when mortality was high, with the trends leveling off or reversing after the later imposition of fishing moratoria. In contrast, females display patterns that are less consistent and expected; significant trends are detected only when accounting for density-dependent effects, with females in two populations unexpectedly showing a long-term decline in gonadal investment. Our results support the hypothesis that fisheries-induced evolution has occurred in gonadal investment in males, but not in females, and suggest that gonadal investment is more important for male reproductive success than expected in this lekking species.

Key words: reproductive investment, fisheries-induced evolution, Atlantic cod, gonad weight

\section{Introduction}

Reproductive investment is jointly determined by several traits, exhibits a strong link with fitness, and is tightly associated with the quantity and quality of offspring. Reproduction has immediate costs in terms of growth (Roff 1983; Reekie and Bazzaz 1992) and survival (Bell 1980; Gunderson 1997); individuals must, therefore, trade off the proportion of resources devoted to reproduction against other fitness components, so that an increased investment in reproduction at a given time is possible only at the expense of an individual's future reproductive output (Williams 1966; Stearns 1992; Heino and Kaitala 1999; Kunz and Orrell 2004). Changes in mortality reshape the fitness benefits of current and future reproductive investments, and hence, the optimal proportion of resources to be invested into reproduction at a given time. Exploitation increases mortality, often considerably, relative to 
natural mortality (Mertz and Myers 1998; Festa-Bianchet 2003). Consequently, the timing of sexual maturation and the schedule of energy allocation to reproduction are expected to evolve toward precocity and increased reproductive investment for each reproduction opportunity when exploitation reduces life expectancy (Hirshfield and Tinkle 1975; Law and Grey 1989; Rijnsdorp 1993; Festa-Bianchet 2003; Heino et al. 2013).

Evidence suggestive of an evolutionary shift toward earlier maturation has been reported for numerous exploited fish populations (see Devine et al. 2012; Audzijonyte et al. 2013; and Heino et al. 2015 for reviews). In contrast, the fisheries-induced evolution of reproductive investment in adult fish is much less studied (Heino et al. 2015). Still, a few studies have provided support for an increase in reproductive investment in response to fishing pressure for a number of fish species (European plaice, Rijnsdorp 1993; Atlantic cod, Yoneda and Wright 2004; common whitefish, Thomas et al. 2009; haddock, Wright et al. 2011; and silver cyprinid, Sharpe et al. 2012). However, alternative or complementary explanations of these trends are conceivable, and the relative importances of the different contributing processes are difficult to determine. For instance, phenotypic changes resulting from the density-dependent availability of resources are regularly put forward as potential explanations for an observed increase in size-specific fecundity (Koslow et al. 1995; Stares et al. 2007).

In this study, we attempt to identify the various factors governing variability in gonadal investment over a 36-year time period in three populations-managed as distinct stocks-of Atlantic cod (Gadus morhua) off Newfoundland: the northern cod stock off southern Labrador and eastern Newfoundland, the southern Grand Bank stock, and the St. Pierre Bank stock (Fig. 1). These populations experienced high levels of mortality, particularly in the early 1990s (Rideout et al. 2013; DFO 2014, 2015). Age and size at maturation have declined in these populations, and these declines are thought to have a significant evolutionary component, with fishing as the likely driving force (Olsen et al. 2004, 2005). In this study, we correspondingly assess the potential evolutionary character of temporal trends in the gonadal investment of these populations. Based on the aforementioned elements of life history theory, we predict an increase in reproductive investment paralleling the decrease in age and size at maturation caused by periods of high mortality, with selection expected to be at its strongest in the early 1990s. We furthermore expect that changes in reproductive investment have leveled off and possibly reversed following the reduction of mortality rates, the duration and timing of which varied among the three populations.

Our analyses in this study are based on an extensive collection of measurements of gonad weights and body weights of individual cod. Because gonadal investment accounts for a major part of the energetic investment into reproduction in female cod (Jørgensen et al. 2008), we expect that the predicted changes in reproductive investment will manifest in females through gonadal investment. In contrast, little is known about energetic investment into reproduction in male cod. Because cod is a lekking species (i.e., males assemble during the mating season to engage in competitive displays on sites visited by females; Hutchings et al. 1999; Nordeide and Folstad 2000), we nevertheless expect that energetic costs of reproduction other than gonadal investment are more important in males than in females. Because lekking is associated with unequal male access to females, it is expected to imply reduced sperm competition. In other fishes, the intensity of sperm competition is positively correlated with relative testis size (Stockley et al. 1997). We, therefore, predict exploitation-induced changes in gonadal investment to be more pronounced in female cod than in male cod.

Below, we start by examining the extent to which fluctuations in gonadal investment can be attributed to individual characteristics, environmental influences, and population demography, before assessing the residual temporal patterns. The purpose of this first step is to account for as much of the demographic and phenotypically plastic variability in gonad weight as possible, before considering the possibility of evolutionary trends as a second step. The presence of significantly positive residual 


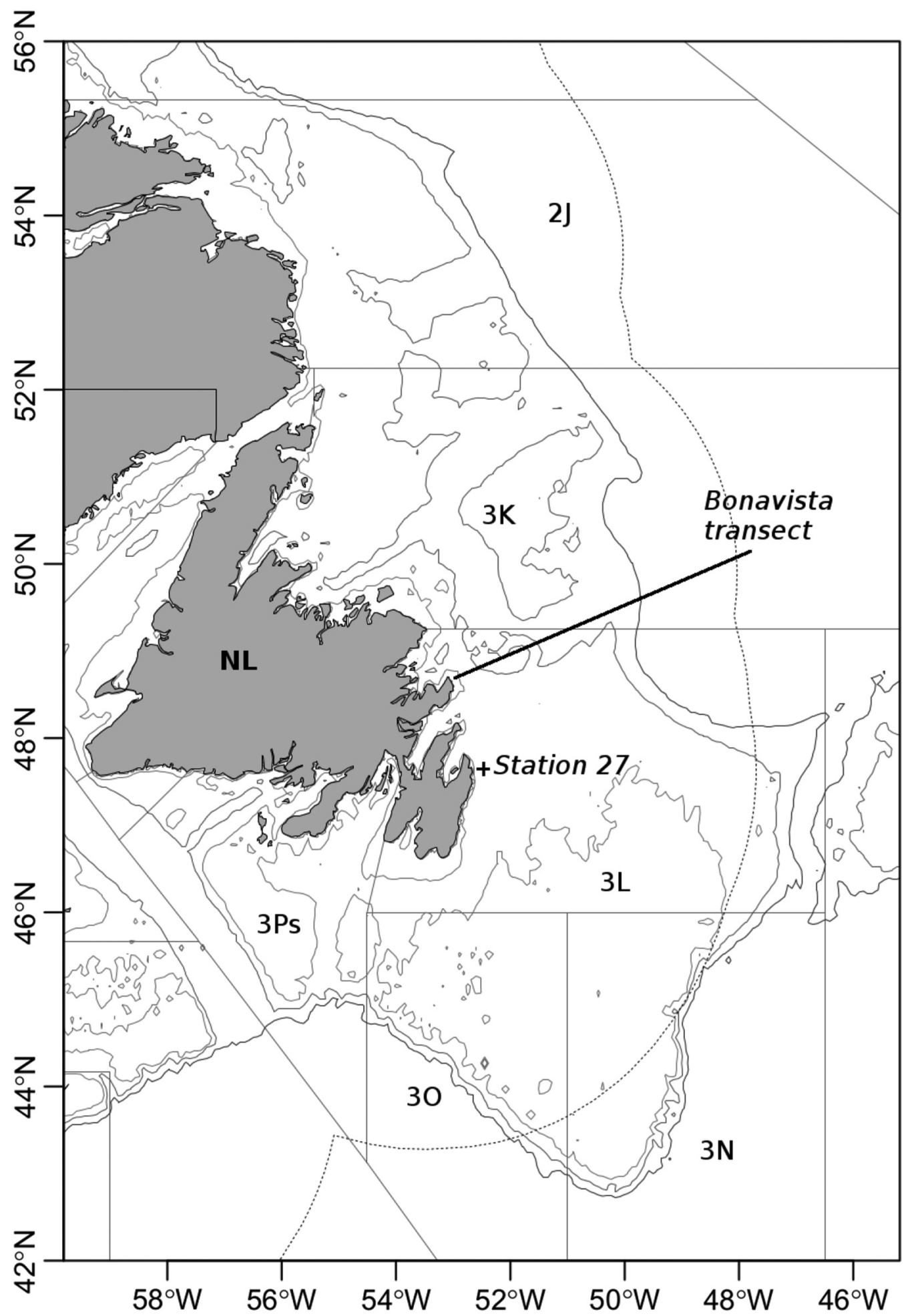

Fig. 1. Study area off Newfoundland (NL), Canada. The locations of Station 27 and the Bonavista transect, where water temperatures and the area of the vertical cross section of the cold intermediate layer (CIL) were measured, are indicated. Stock distributions: Divisions 2J3KL, northern cod stock; Divisions 3NO, southern Grand Bank cod stock; Subdivision 3Ps, St. Pierre Bank cod stock. Basemap produced using ACON data visualization software. 
trends during the period of heavy exploitation, followed by a leveling off or even reversal of such trends after fishing pressure declined-with a delay that is similar to the time interval between spawning and when the resulting offspring start making a significant contribution to the spawning stockwould support the hypothesis that reproductive effort in cod off Newfoundland has evolved in response to fishing.

\section{Materials and methods}

\section{Cod populations and mortality regimes}

Three cod populations were considered in this study (Fig. 1): the northern cod stock (NAFO Divisions 2 J, $3 \mathrm{~K}$, and $3 \mathrm{~L}$ ), for which data from only Division $3 \mathrm{~L}$ were available; the southern Grand Bank cod stock (NAFO Divisions $3 \mathrm{~N}$ and 3O); and the St. Pierre Bank cod stock (NAFO Subdivision 3Ps). The pattern in fishing mortality experienced by each of these populations since the late 1950s or early 1960s is available from cohort analyses (Bishop et al. 1993; Brattey et al. 2001; Rideout et al. 2013). Because cohort analyses have not been accepted as being representative of the population dynamics of the northern cod stock since 1993 and of the St. Pierre Bank stock since 2005 , trends in total mortality of these stocks have also been deduced from catch rates during bottomtrawl surveys. Mortality values derived from these two approaches (models of population dynamics and catch-rate analysis) do not always coincide and can display a high interannual variability.

Nevertheless, periods with different mortality regimes can be identified. Fishing mortality increased during the 1960s and early 1970s and then decreased considerably in the late 1970s, as limitations on international fishing fleets resulting from the establishment of the Canadian 200 nautical mile exclusive economic zone came into effect. Fishing mortality increased again through the latter half of the 1980s and into the early 1990s, prompting the introduction of moratoria between 1992 and 1994 on directed fishing for each of the three cod stocks. For the northern cod stock, the moratorium remains in effect for the offshore, but relatively small directed fisheries have been permitted in the inshore between 1998 and 2002 and from 2006 to the present. The southern Grand Bank stock remains under a moratorium, but directed fishing on the St. Pierre Bank stock recommenced in 1997. For the northern cod stock, the cessation of directed fishing did not immediately result in a reduction of mortality, as total mortality computed from the research surveys continued to be very high for at least a decade (average total instantaneous mortality rate $Z=1.05$ year $^{-1}$ over the period from 1995 to 2005, for individuals between ages 4 and 6 years), presumably because of heightened natural mortality (Lilly et al. 2013). Total mortality appears to have declined during the most recent decade (DFO 2014). For the southern Grand Bank stock, fishing mortality declined to very low levels after the introduction of the moratorium (average $Z=0.40 \mathrm{year}^{-1}$ between 1995 and 2000 for ages 4-6 years) but increased to moderate levels for about a decade because of high bycatch (average $Z=0.53$ year $^{-1}$ between 2001 and 2010 for ages 4-6 years; Shelton and Morgan 2005; Rideout et al. 2013). Fishing mortality has been low since 2008 (Rideout et al. 2013). For the St. Pierre Bank stock, fishing mortality declined to a very low level for the three full years of the moratorium (average $F=0.005$ year $^{-1}$ for ages 4-6 years; Brattey et al. 2001) and then increased to a moderate level when fishing recommenced (average $F=0.076$ year $^{-1}$ between 1997 and 2001 for ages 4-6 years; Brattey et al. 2001). Total mortality, as estimated from research vessel surveys, has been moderately high for the past decade (DFO 2015).

\section{Sampling}

All samples were collected during stratified-random bottom-trawl surveys conducted in the spring by Fisheries and Oceans Canada (DFO) from 1978 to 2013. The surveys took place during the early part of the spawning season (with the middle of the spawning season usually occurring in May or June; Hutchings and Myers 1994). For each trawl haul, the date, position, and bottom depth were recorded. 
The fish caught were subsampled by length classes, sexed, and aged by otolith reading; their length was measured to the nearest centimeter; and their gutted weight, as well as the weights of their livers and gonads, was recorded. The maturity stage of the gonads was defined based on morphological criteria, according to a classification scheme adapted from Templeman et al. (1978).

Only females with ovaries exclusively containing opaque eggs visible to the naked eye, corresponding to stage "Mat A-P" of Templeman et al. (1978), were selected for analyses. This selection was made to prevent the weight of gonads being affected by the hydration of the oocytes, which would lead to an increase in gonad weight that did not reflect changes in the actual energetic reproductive investment, and to reduce the risk of the inclusion of fish that had already begun to spawn. Correspondingly, only males with thick but non-running testes, corresponding to maturity stage "Mat $\mathrm{P}$ " of Templeman et al. (1978), were selected for analyses. However, a few isolated peaks were noticed in the distributions of GSI values. To remove these suspicious observations, individuals with a gonadosomatic index (GSI, defined here as gonad weight divided by gutted weight $W_{\text {gutted }}$ ) below $2 \%$ were removed from the analyses ( $10.2 \%$ of individuals on average). We suspect that some females had already started to spawn at the time of sampling and no longer contained hydrated oocytes; these individuals would, thus, have been erroneously classified as pre-spawning with an abnormally low gonad weight. An analogous filtering was applied to males, because a bimodal distribution of their GSI values, with a peak at very low GSI values $(<1 \%)$, suggested that some of them may also have been misclassified ( $4.5 \%$ of individuals on average). Furthermore, to reduce the influence of declining numbers of old cod in the later part of the time series, individuals older than 10 years were excluded from the analysis. The final numbers of individuals used for the analyses are given in Table 1.

All experiments proceeded according to the Canadian Council on Animal Care guidelines (CCAC 2005).

\section{Variables for explaining gonad weight}

To explain the variability in gonad weight, we explored a number of variables describing the sampled individuals, sampling times and locations, and overall environmental conditions.

To account for individual body condition, the relative liver index was used as an explanatory variable, which is not confounded by the allometry between liver weight and body weight. This index is defined as $W_{\text {liver }} / W_{\text {liver }}$ (predicted), where the predicted liver weight is obtained from the allometric relationship $W_{\text {liver }}$ (predicted $)=a W_{\text {gutted, }}^{b}$ with parameters $a$ and $b$ estimated separately for each sex and stock.

To account for seasonal effects, the sampling time during the year was used as an explanatory variable, expressed as the day of the year on which the sampling occurred (from 1 to 365 or 366).

To account for spatial effects, sampling position was used as an explanatory variable, described by its latitude $\left({ }^{\circ} \mathrm{N}\right)$, longitude $\left({ }^{\circ} \mathrm{W}\right)$, and bottom depth.

To account for density-dependent effects, stock biomass was used as an explanatory variable. Indices of stock biomass originate from the same surveys as individual biological data. The first year for which stock indices are available is 1985 for Division 3L, 1984 for Divisions 3NO, and 1983 for Subdivision 3Ps. No suitable biomass indices are available from earlier surveys because no method yet exists to make data collected with earlier and present sampling protocols comparable. This limitation restricts the time span over which stock biomass indices can be included as an additional explanatory variable in the statistical analyses below. The most recent year of the series considered is 2013.

To account for temperature effects, ocean temperature was used as an explanatory variable, considering two time series reflecting ocean temperature (Fig. 2). The first time series is the mean annual 
Table 1. Sample sizes by year, stock, and sex.

\begin{tabular}{|c|c|c|c|c|c|c|}
\hline Year & 3L females & 3L males & 3 NO females & $3 \mathrm{NO}$ males & 3Ps females & 3Ps males \\
\hline 1978 & 16 & 9 & 7 & 2 & 9 & 17 \\
\hline 1979 & 11 & 3 & 13 & 0 & 15 & 20 \\
\hline 1980 & 21 & 15 & 17 & 29 & 23 & 31 \\
\hline 1981 & 42 & 28 & 22 & 57 & 34 & 17 \\
\hline 1982 & 30 & 42 & 33 & 21 & 19 & 30 \\
\hline 1983 & 0 & 0 & 0 & 0 & 27 & 35 \\
\hline 1984 & 10 & 31 & 21 & 43 & 19 & 19 \\
\hline 1985 & 23 & 21 & 47 & 37 & 15 & 14 \\
\hline 1986 & 13 & 35 & 47 & 53 & 16 & 19 \\
\hline 1987 & 15 & 25 & 21 & 25 & 31 & 31 \\
\hline 1988 & 0 & 0 & 0 & 0 & 27 & 36 \\
\hline 1989 & 3 & 9 & 13 & 9 & 54 & 46 \\
\hline 1990 & 39 & 59 & 75 & 107 & 85 & 85 \\
\hline 1991 & 32 & 53 & 63 & 72 & 109 & 102 \\
\hline 1992 & 22 & 30 & 38 & 50 & 118 & 122 \\
\hline 1993 & 19 & 23 & 69 & 54 & 97 & 64 \\
\hline 1994 & 12 & 33 & 24 & 40 & 109 & 99 \\
\hline 1995 & 5 & 4 & 21 & 37 & 133 & 191 \\
\hline 1996 & 8 & 20 & 30 & 89 & 126 & 167 \\
\hline 1997 & 0 & 21 & 33 & 48 & 40 & 51 \\
\hline 1998 & 8 & 17 & 47 & 53 & 122 & 85 \\
\hline 1999 & 5 & 24 & 46 & 57 & 102 & 60 \\
\hline 2000 & 4 & 10 & 11 & 13 & 91 & 77 \\
\hline 2001 & 27 & 14 & 8 & 20 & 67 & 50 \\
\hline 2002 & 23 & 17 & 17 & 17 & 51 & 55 \\
\hline 2003 & 16 & 8 & 24 & 31 & 59 & 32 \\
\hline 2004 & 1 & 8 & 26 & 36 & 60 & 58 \\
\hline 2005 & 9 & 8 & 28 & 30 & 66 & 71 \\
\hline 2006 & 10 & 16 & 0 & 0 & 0 & 0 \\
\hline 2007 & 1 & 5 & 6 & 17 & 59 & 51 \\
\hline 2008 & 6 & 8 & 13 & 4 & 41 & 50 \\
\hline 2009 & 16 & 33 & 17 & 25 & 40 & 73 \\
\hline 2010 & 12 & 14 & 6 & 21 & 50 & 63 \\
\hline 2011 & 21 & 51 & 29 & 25 & 67 & 78 \\
\hline 2012 & 30 & 46 & 14 & 17 & 156 & 150 \\
\hline 2013 & 58 & 37 & 61 & 61 & 70 & 79 \\
\hline
\end{tabular}

Note: 3L, northern cod stock; 3NO, southern Grand Bank cod stock; 3Ps, St. Pierre Bank cod stock. 


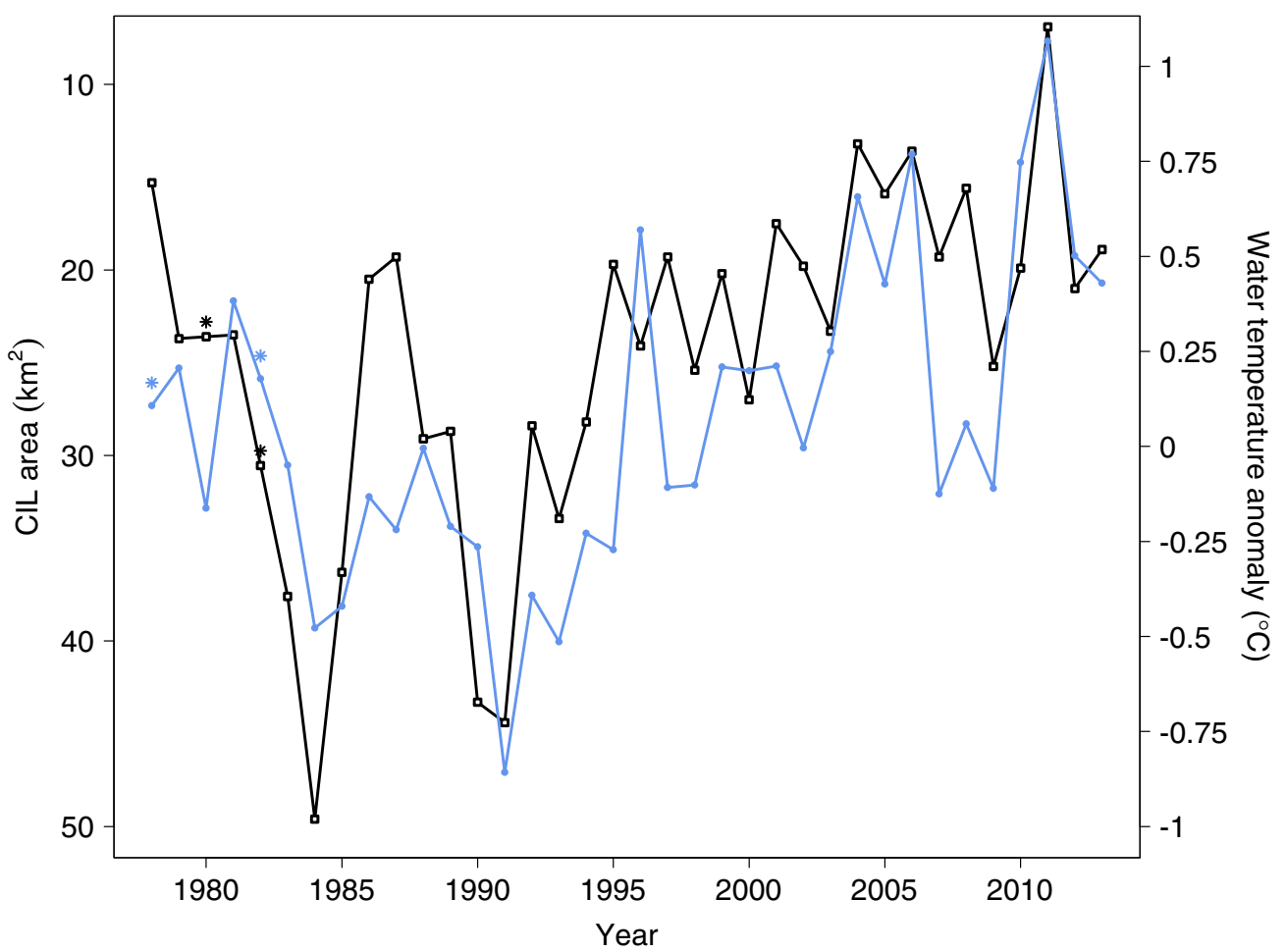

Fig. 2. Time series of water temperature anomaly measured at Station 27 (blue; right vertical axis), and area of the vertical cross section of the cold intermediate layer (CIL) measured along the Bonavista transect (black; left vertical axis—notice inverted scale). Asterisks indicate interpolated values.

temperature across all depths $(0-175 \mathrm{~m})$ measured at the hydrographic monitoring Station $27\left(47^{\circ} 32.8^{\prime} \mathrm{N}, 52^{\circ} 35.2^{\prime} \mathrm{W}\right)$, located about $7 \mathrm{~km}$ off St. John's (Newfoundland, Canada; Fig. 1). The deviation of this temperature from its long-term mean (1981-2010) (i.e., the temperature anomaly) was used to represent changes in the average temperature conditions for all stocks. Although Station 27 is located in the inshore branch of the Labrador Current, temperatures measured there are representative of ocean temperatures over the Newfoundland Shelf up to a depth of $175 \mathrm{~m}$ (Petrie et al. 1991). The second time series is the area of the vertical cross section of the cold intermediate layer (CIL) along the Bonavista transect (Fig. 1) measured during summer. The CIL is a layer of cold water $\left(<0{ }^{\circ} \mathrm{C}\right)$ between the seasonally heated surface layer and the warmer bottom layer originating from the continental slope (DFO 2008). In comparison with water at Station 27, the CIL represents a deeper water column, has a broader cross-shelf extent, and is less influenced by nearsurface conditions. The larger the CIL area, the colder the oceanographic conditions during the previous winter and spring. As measurements are not available for the years 1978 and 1982 (water temperature anomaly) or 1980 and 1982 (CIL area), the missing values were estimated through linear interpolation. For both of these time series, the extent to which they represent conditions at a biological sampling site likely declines with the distance from that site (Petrie et al. 1991).

\section{Statistical analyses}

Following Roff (1983) and Tomkins and Simmons (2002), we assume that gonad weight is allometrically related to body weight, $W_{\text {gonad }}=a W^{b}$ body, where $a$ is a scaling parameter and $b$ is the allometric exponent. This formulation is preferable to using GSI as the response variable because it allows the estimation of the allometric relationship, rather than being confounded by it. As a special case, 
isometry $(b=1)$ applies when gonad weight is proportional to body weight, whereas $b>1$ corresponds to positive allometry (relative gonad weight increases with body weight). By logarithmic transformation of weight measurements, the above equation can be fitted to data using a generalized linear model. The simplest model, without additional explanatory variables, thus, takes the form:

$\log \left(W_{\text {gonad }}\right)=a^{\prime}+b \log \left(W_{\text {body }}\right)$, with $a^{\prime}=\log (a)$

We estimated this model as a generalized linear model with a logarithmic link function and gamma error distribution; the latter was chosen to account for the observed increase of variance in gonad weight with body weight. Body weight was always measured as gutted weight (rather than as total body weight) to remove the confounding effect of the weight of the contents of the stomach and intestine.

We treated stocks and sexes independently and estimated separate models for the entire time span covered by the biological data (1978-2013) and for the shorter time span also covered by biomass data (1983/1984/1985-2013, depending on the stock). For both time spans, we considered the following as potential explanatory variables: gutted weight (log-transformed), age, body condition (relative liver index), sampling day, the geographical coordinates and depth of the sampling station, NAFO division (for the southern Grand Bank stock), annual water temperature anomaly, and CIL area. For all tested variables, we applied a significance threshold of 0.01 , to reduce false positives (type-I errors).

The model selection in our analyses was performed as follows. We started from a model including all explanatory variables apart from sampling year, as well as three interactions judged a priori as being potentially important, as follows: the interaction between age and gutted weight, the interaction between relative liver index and sampling day (to account for a potential decrease of the relative liver index at the expense of gonads during a season), and the interaction between temperature and sampling day (to account for the potential influence of temperature-induced changes in spawning time). Regarding this last interaction, both CIL area and water temperature anomaly were tested to represent temperature variability. We then identified the best model using AIC-based stepwise model selection, i.e., stepwise deletion or addition of a single term that results in the lowest AIC during each step. After that, the significance of the linear and quadratic effects of sampling year, added as the last explanatory variables, was evaluated using a likelihood-ratio test. The quadratic effect was included to allow for nonlinear time trends; in particular, for the leveling off and reversal of time trends following reductions in fishing pressure. Because the latter effects are expected to be gradual, a quadratic term is more suitable than a change-point approach to account for them. To be able to test and interpret linear and quadratic effects independently (Schielzeth 2010), the quadratic term for sampling year was centered such that the middle of each time series corresponded to the value zero. When considering the shorter time spans for which biomass data are available (1983/1984/1985-2013, depending on the stock), the best model was selected in the same way as for the full time series, but with the stock biomass index included as a potential additional explanatory variable. This resulted in 12 final models, one for each combination of sex (2 levels), stock (3 levels), and time span (2 levels).

We illustrate the results of our statistical analyses by presenting model-predicted GSI values for a standardized, "typical" individual with a gutted weight of $900 \mathrm{~g}$. Whenever relevant, the following reference values are used: an age of 5 years; a relative liver index of 1; a sampling day of 1 May; a sampling depth of $100 \mathrm{~m}$; the average longitude and latitude of samples in the considered NAFO area(s); a water temperature anomaly of $0{ }^{\circ} \mathrm{C}$; a CIL area of $26 \mathrm{~km}^{2}$ (corresponding to the average over the years 1978-2013); and stock biomass indices of $9.1710^{4}$ metric tons for Division 3L, $1.3210^{5}$ metric tons for Divisions 3NO, and $6.5810^{4}$ metric tons for Subdivision 3Ps (corresponding to the averages for each stock during the study period). 


\section{Results}

Without any standardization other than by maturity stage, it appears that the metric traditionally used to measure gonadal investment, the GSI, shows high variability among individuals sampled in any given year, as well as between years, without any obvious temporal trends (Fig. 3). Values for males and females are relatively similar for each of the populations considered, with the average of the annual mean varying between 6.7\% (females in Subdivision 3Ps) and 11.1\% (males in Divisions $3 \mathrm{NO}$ ). To better understand the drivers of this variability in GSI, we turn to the statistical models for explaining gonad weight.

The generalized linear models capture a large part of the variability in gonad weight (Table 2), as indicated by the pseudo-coefficient of determination $\left(R^{2}\right)$. Overall, between $79 \%$ and $90 \%$ of the total variability in gonad weight is accounted for by the models before inclusion of the sampling year; the main part of the explained variability is always captured by gutted weight (between $70 \%$ and $89 \%$ of total deviance). For any given population, the best model for males explains a larger part of the variability than for females (paired Student's $t$-test on $R^{2}, n=6, t=14.4, p<0.001$ for the full time series without inclusion of the sampling year). Allometric exponents in the relationship between gonad weight and body weight are estimated to be significantly higher than 1 (positive allometry) for males in all populations and for females in two populations (Division 3L and Subdivision 3Ps); the allometric exponents in the models for females in Divisions $3 \mathrm{NO}$ were not significantly different from 1 and implied an isometric relationship between gonads and soma (Table 2).
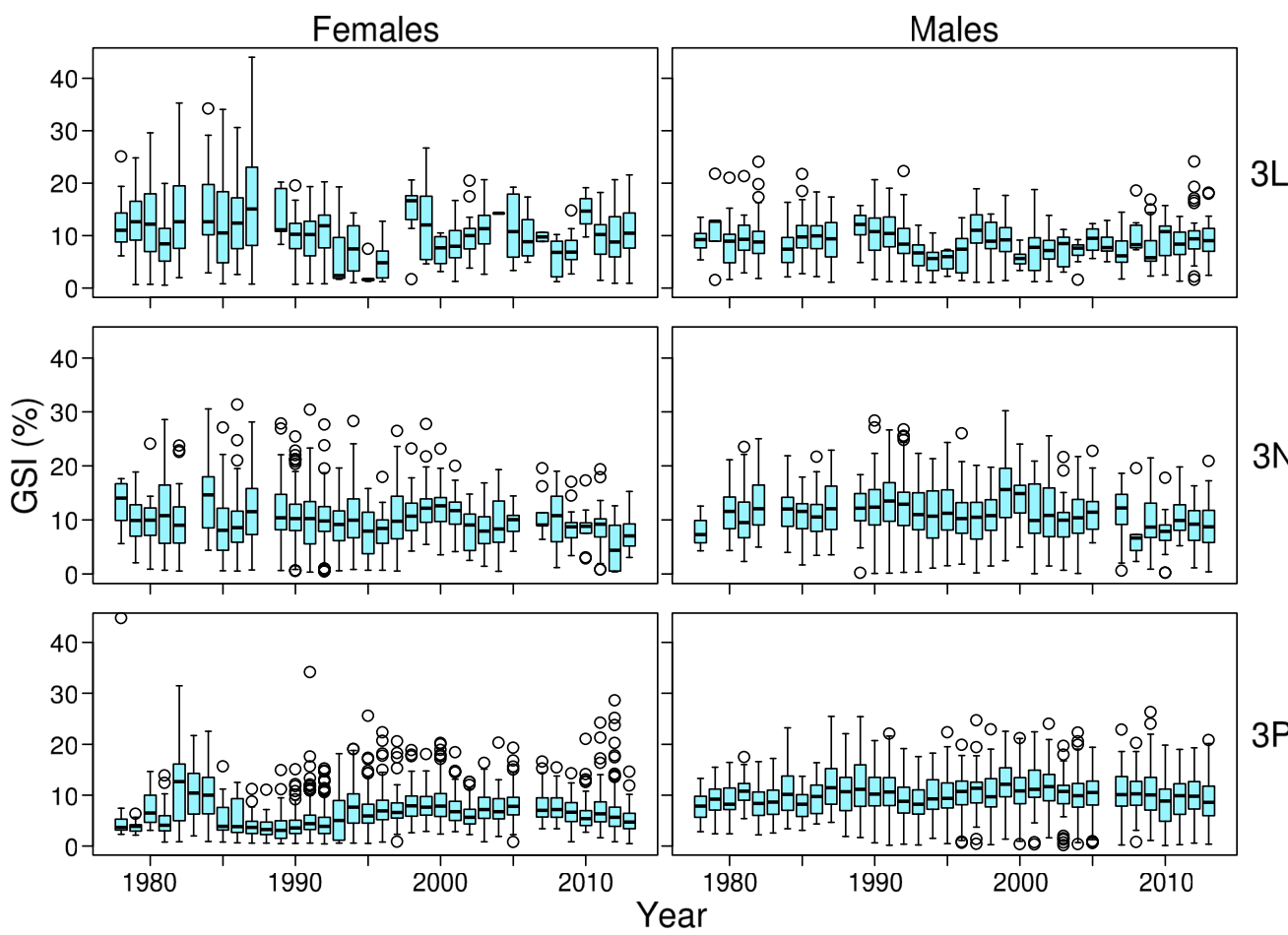

Fig. 3. Distributions of observed GSI values for each stock, sex, and year. Median values are indicated by thick horizontal lines. Coloured boxes delineate the interquartile ranges. Whiskers extend either to maximal/minimal values or to 1.5 times the interquartile range when the latter is smaller; individual observations beyond this range are represented by open circles. GSI, gonadosomatic index; 3L, northern cod stock; 3NO, southern Grand Bank cod stock; 3Ps, St. Pierre Bank cod stock. 
Table 2. Generalized linear models that best describe the variability in gonad weight.

\begin{tabular}{|c|c|c|c|c|c|c|c|c|c|}
\hline Stock & Sex & Years & $\begin{array}{l}\text { Sample } \\
\text { size }\end{array}$ & $\begin{array}{l}\text { Explanatory terms in the } \\
\text { best model, in addition } \\
\text { to gutted weight }\end{array}$ & $\begin{array}{l}\text { Allometric } \\
\text { exponent } \\
\text { (SE) }\end{array}$ & $\begin{array}{l}R^{2} \text { for model } \\
\text { without year } \\
\text { effect }(\%)\end{array}$ & $\begin{array}{l}\text { Significance } \\
\text { of year } \\
\text { effect, } p\end{array}$ & $\begin{array}{l}\text { Relative } \\
\text { annual } \\
\text { rate of } \\
\text { change (\%) }\end{array}$ & $\begin{array}{l}R^{2} \text { for model } \\
\text { with year } \\
\text { effect }(\%)\end{array}$ \\
\hline \multirow[t]{4}{*}{$3 \mathrm{~L}$} & \multirow[t]{2}{*}{$\mathrm{F}$} & $1978-2013$ & 516 & + day + lon +age + age $\times \mathrm{W}$ & $1.50(0.13)$ & 79.6 & 0.186 & -0.34 & 79.7 \\
\hline & & $1985-2013$ & 398 & +day +LI +age +lon & $1.14(0.07)$ & 79.0 & 0.239 & -0.37 & 79.1 \\
\hline & \multirow[t]{2}{*}{$\mathrm{M}$} & $1978-2013$ & 747 & $\begin{array}{c}\text { +day + +age }-\mathrm{CIL} \text {-age } \times \mathrm{W} \\
+ \text { year }- \text { year }^{2}\end{array}$ & $1.36(0.07)$ & 86.2 & $<0.001$ & +0.76 & 86.7 \\
\hline & & $1985-2013$ & 622 & + day +year -year ${ }^{2}$ & $1.35(0.02)$ & 85.7 & 0.006 & +0.57 & 86.1 \\
\hline \multirow[t]{4}{*}{$3 \mathrm{NO}$} & \multirow[t]{2}{*}{$\mathrm{F}$} & $1978-2013$ & 827 & + day $+\mathrm{LI}+$ age + lat & $1.06(0.03)$ & 82.1 & 0.102 & -0.33 & 82.2 \\
\hline & & $1984-2013$ & 746 & $+\mathrm{LI}+$ day +age $-\mathrm{B}-$ year & $1.02(0.04)$ & 82.8 & 0.001 & -0.87 & 83.1 \\
\hline & \multirow[t]{2}{*}{$\mathrm{M}$} & $1978-2013$ & 1134 & $\begin{array}{l}\text { +age +day +lon +LI +T } \\
-\mathrm{LI} \times \text { day +year }- \text { year }^{2}\end{array}$ & $1.19(0.02)$ & 89.9 & $<0.001$ & +0.54 & 90.1 \\
\hline & & $1984-2013$ & 1025 & $\begin{array}{c}\text { +age +day +lon +LI -B } \\
+ \text { T }- \text { LI } \times \text { day }- \text { year }^{2}\end{array}$ & $1.19(0.02)$ & 89.9 & 0.282 & +0.14 & 90.0 \\
\hline \multirow[t]{4}{*}{$3 \mathrm{Ps}$} & \multirow[t]{2}{*}{$\mathrm{F}$} & $1978-2013$ & 2010 & $\begin{array}{l}+ \text { day }+\mathrm{LI}+\mathrm{CIL}+\text { age } \\
\quad+\text { lon }- \text { age } \times \mathrm{W}\end{array}$ & $1.24(0.07)$ & 78.9 & 0.020 & -0.39 & 78.9 \\
\hline & & $1983-2013$ & 1922 & $\begin{array}{c}\text { +day +LI +age +lon } \\
+ \text { CIL -age } \times \text { W }-\mathrm{B}-\text { year }\end{array}$ & $1.25(0.08)$ & 78.8 & 0.004 & -0.58 & 78.9 \\
\hline & \multirow[t]{2}{*}{$\mathrm{M}$} & $1978-2013$ & 2133 & $\begin{array}{c}\text { +age }+\mathrm{LI}+\text { day }+ \text { lon } \\
+\mathrm{T} \text {-age } \times \mathrm{W}-\mathrm{LI} \times \text { day } \\
+ \text { year }- \text { year }^{2}\end{array}$ & $1.31(0.04)$ & 87.1 & $<0.001$ & +0.93 & 87.6 \\
\hline & & $1983-2013$ & 2018 & $\begin{array}{c}\text { +age }+\mathrm{LI}+\text { day }+ \text { lon } \\
+\mathrm{T}-\text { age } \times \mathrm{W}-\mathrm{LI} \times \text { day } \\
+ \text { +year }- \text { year }^{2}\end{array}$ & $1.32(0.04)$ & 87.4 & $<0.001$ & +0.63 & 87.6 \\
\hline
\end{tabular}

Note: Gutted weight is always included as an explanatory variable to account for the dependence of gonad weight on body weight. All models assume a logarithmic link function and a gamma error distribution, so that the explanatory variables have multiplicative effects on gonad weight. In the fifth column, the signs of explanatory variables indicate the direction of their influences on gonad weight, and $\times$ indicates an interaction effect. F, female; $M$, male; W, gutted weight of individual; LI, relative liver index of individual; age, age of individual; day, sampling day (day of the year); lon, sampling longitude; lat, sampling latitude; depth, sampling depth; year, sampling year; CIL, area of the vertical cross section of the cold intermediate layer; T, water temperature anomaly; B, stock biomass index; $R^{2}$, McFadden's pseudo-coefficient of determination. The allometric exponent is the coefficient associated with the logarithm of gutted weight and, therefore, describes the allometry of gonad weight with respect to gutted weight; a value of 1 corresponds to an isometric relationship. Bold text shows where the effects of sampling year indicative of residual temporal trends are significant. Rate estimates refer to a model with only a linear effect of sampling year, even when the quadratic effect of sampling year is significant. 
In addition to gutted weight, two individual-level explanatory variables frequently appear in the best models for explaining the variability in gonad weight (Table 2). When significant (in 9 out of 12 cases), body condition, measured in terms of the relative liver index, always has a positive effect, implying that fish with a high relative liver weight tend to have large gonads for their body weight. The age of sampled individuals is also significant in all but one case. Age, independently of body weight, shows a positive linear relationship with gonad weight, implying that older fish tend to have larger gonads for their size. In six instances, the interaction between age and gutted weight (log transformed) is significant. Yet, this interaction has opposite effects on gonad weight, being positive for females in Division 3L, and negative for both sexes in Subdivision 3Ps and for males in Division 3L. Notice that the interaction between sampling day and CIL area or water temperature anomaly is never retained in the best models.

Sampling characteristics also explain some variability in gonad weight (Table 2). The sampling day is always a significant explanatory variable with a positive effect: on average, the gonad weight of cod in prespawning condition increases during the course of a season. Furthermore, the sampling location is significant in several cases (females in Divisions $3 \mathrm{~L}$ and $3 \mathrm{NO}$ for the short time series, males in Divisions 3NO, and both sexes in Subdivision 3Ps), even though the NAFO division is not retained in the best models describing the gonad weight of cod sampled in Divisions 3NO. When a geographical effect is significant, it mostly appears as a longitudinal gradient (gonad weight tends to increase westward), whereas latitude is significant only for the full time series for females in Divisions 3NO.

The two large-scale environmental variables, water temperature anomaly and CIL area, are only present in a few of the best models (appearing, respectively, in four and three of the 12 selected models; Table 2). Moreover, these factors usually explain a relatively small proportion of the variability in gonad weight (always $\leq 1 \%$ ). The effect of the water temperature anomaly on gonad weight is always positive, whereas the sign of the coefficient associated with the CIL area is not consistent across data sets, being negative for males in Division 3L, and positive for females in Subdivision 3Ps.

Sampling year was added as an explanatory variable only in the final step of the model selection procedure (Table 2). For the full time series, adding the linear effect of sampling year always significantly improves the models and is positive for males. Allowing for a quadratic effect of sampling year improves the fit for males, with its negative sign suggesting that the temporal trend has been leveling off or even reversing from around the mid-1990s onward (Table 2 and Fig. 4). For females, the linear effect of year is never significant for the full time series.

Finally, we considered whether the changes in gonad weight can be attributed to density-dependent effects. This analysis is handicapped by a lack of stock biomass data before 1983 (Subdivision 3Ps), 1984 (Divisions 3NO), or 1985 (Division 3L). Truncating the time series, without yet considering the stock biomass index as a new explanatory variable, does not change the main results for males: the introduction of long-term trends significantly improves the model fits in all populations (results not shown). When biomass is accounted for (Table 1), results are unchanged for males in Division $3 \mathrm{~L}$ and in Subdivision 3Ps, but the linear trend disappears for males in Divisions 3NO (where, however, a significant negative quadratic term remains, implying a significantly dome-shaped long-term pattern). For females, accounting for biomass has an unexpected consequence in Divisions 3NO and in Subdivision 3Ps, making the linear effect of year significant and negative.

The model-predicted GSI series (Fig. 4) show very similar values between populations and sexes after accounting for demographic and environmental influences; the variability seen in Fig. 3 could, thus, largely reflect differences in demographic and environmental factors affecting gonad weight (in particular, gutted weight) between populations. For a standard fish, the predicted GSI lies within the range of $5 \%-9 \%$. The estimated relative annual rate of increase in gonad weight or GSI, when 


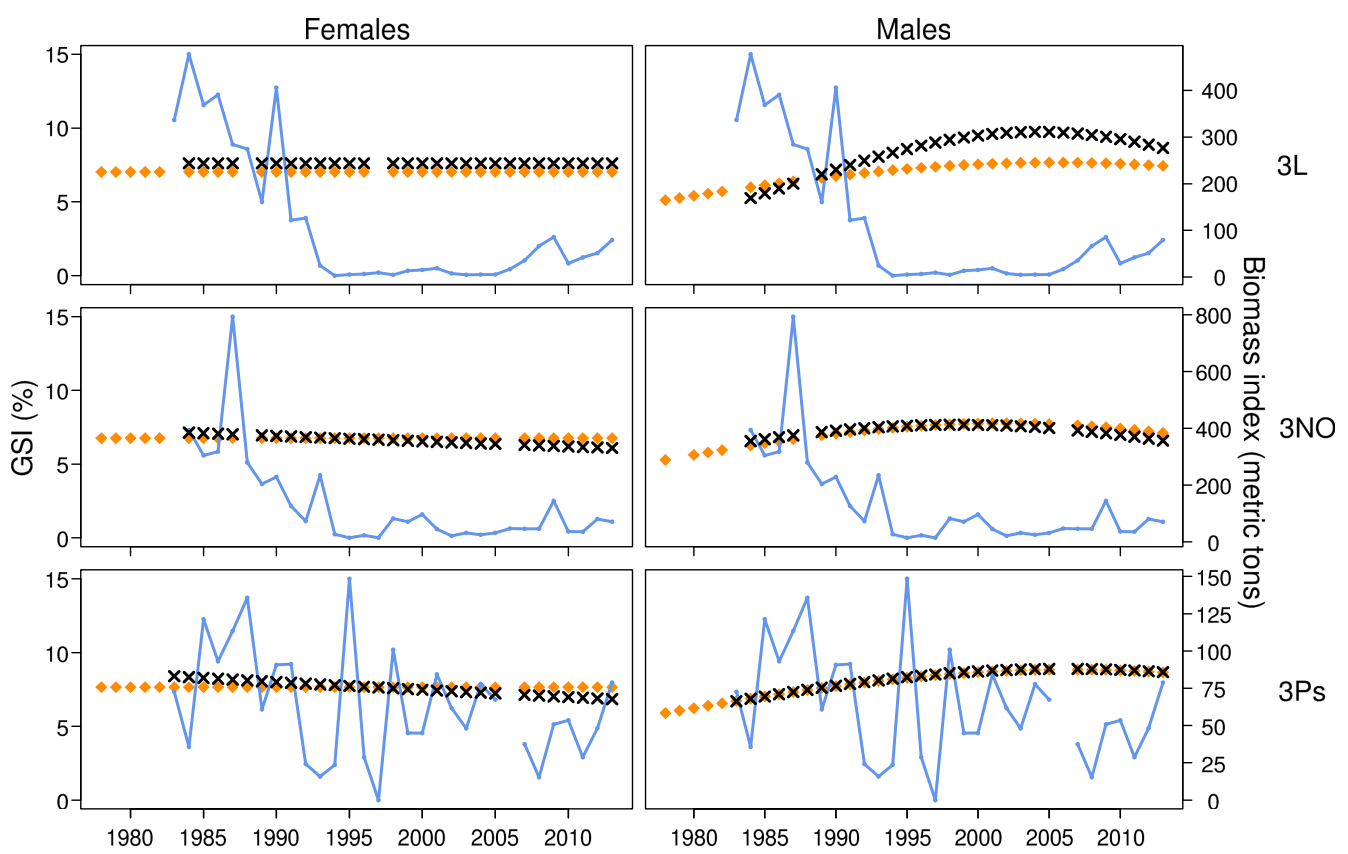

Fig. 4. Trends in predicted GSI values for each stock, sex, and year obtained for a standard individual (as defined in the section "Statistical analyses") from the models in Table 2. Predictions from models fitted over the full time span 1978-2013 are shown as orange diamonds, whereas predictions from models fitted over the shorter time span for which the stock biomass index is available as a potential extra explanatory variable are shown as black Xs. Stock biomass indices are shown in blue (right vertical axis). GSI, gonadosomatic index; $3 \mathrm{~L}$, northern cod stock; 3NO, southern Grand Bank cod stock; 3Ps, St. Pierre Bank cod stock.

significant, ranges from $0.53 \%$ (full time series for males in Divisions $3 \mathrm{NO}$ ) to $0.89 \%$ (full time series for males in Subdivision 3Ps). This corresponds to a total increase in GSI of $17.2 \%-30.4 \%$ over a 30 year period.

\section{Discussion}

Our results show that gonadal investment in cod off Newfoundland is highly variable, but shows significant long-term patterns. For male cod, our findings agree with the prediction of life history theory that reproductive investment will increase during periods of high fishing mortality, and that reduced fishing mortality will cause such a trend to level off, eventually reversing it. Surprisingly, we do not find a similar pattern for female cod, despite our prior expectation that females, because of their more direct link between gonadal investment and fitness, should show a stronger pattern than males. This expectation should have applied especially to a species with a lek-like mating system, which is prone to reduce sperm competition among courting males compared with communal spawning. Before discussing possible causes of this difference, we first discuss other drivers of variability in gonad weight.

\section{Interpretation of the effects of explanatory variables other than sampling year}

The single most important variable explaining variability in gonad weight is, as expected, body weight: larger fish have larger gonads. According to our findings, this relationship is isometric only for females in one of the three studied populations. For females in the other two populations and for males in all three populations, the relationship shows positive allometry, so that GSI increases with 
body weight. We are not aware of earlier studies documenting such positive allometry in male cod, although it has been demonstrated in other species (Stoltz et al. 2005).

Because the primary drivers of variation in gonad weight, beyond the effect of body weight, are poorly known in the cod populations studied here, we have tested an array of candidate explanatory variables, using standard model selection techniques to find the "best" model for each combination of sex, stock, and time span. When reporting on the resulting 12 models, there is an increased risk of a significant effect appearing by chance alone. We have reduced this risk of spurious effects by testing only variables and interactions that we considered biologically reasonable a priori, and when in doubt, we have checked that our main conclusions do not depend on including potentially spurious effects.

Among individual-level explanatory variables, the best models often include the relative liver index, which shows a positive relationship with gonad weight. This result is biologically expected and in agreement with earlier studies by Yoneda and Wright (2004), who reported a positive correlation between the relative liver index and the potential fecundity of female cod for various stocks off Scotland, and by Skjæraasen et al. (2006), who found a weak positive relationship between potential fecundity and lipid content at the time of spawning in cod (in cod, lipids are mainly stored in the liver; Kjesbu et al. 1991; Lambert and Dutil 1997). The influence of the relative liver index turns out to be relatively weak in our study as well. Similarly, McIntyre and Hutchings (2003) concluded that, after accounting for the effect of body weight, accounting for the effect of the body condition index did not significantly improve the description of the potential fecundity of cod.

Among other significant explanatory variables, those accounting for sampling day (day of the year) and sampling location (longitude and latitude) frequently explain some variability in gonadal investment (with sampling day and longitude accounting for more variability than latitude). As sampling date and sampling location are only weakly correlated, we consider it likely that these statistically estimated effects are real biological effects. The increase in gonad weight throughout the season, accounted for in all our 12 models via the inclusion of the sampling day, illustrates the variability in gonad weight within the considered maturity stages. A significant geographical gradient could reflect a movement of individuals in the most advanced maturity stages toward spawning sites. This is in line with earlier reports of the geographic distribution of cod individuals depending on their maturity stage (Morgan and Trippel 1996; Lawson and Rose 2000; Robichaud and Rose 2003). These studies, together with direct tank observations (Hutchings et al. 1999), suggest the existence of a lek-like mating system in the studied cod populations, with male cod in spawning condition found on the continental shelf together with spawning females, whereas females with premature ovaries and spent females are more abundant on the continental slope.

Interpreting the relationships between gonad weight and water temperature anomaly (showing a positive correlation when present) and between gonad weight and the area of the vertical cross section of the CIL (showing positive or negative correlations when present) requires some care. The CIL area and water temperature anomaly are negatively correlated (Pearson's correlation coefficient $r=-0.70$ for the years 1978-2013), and they never occur together in any of the 12 best models. Although the measurements underlying water temperature anomaly and CIL area are partly taken in Division $3 \mathrm{~L}$ and are, thus, thought to reflect conditions in this division, they are also thought to be representative of the prevailing environmental conditions in Divisions 3NO, but less so those in Subdivision 3Ps. The estimated effect on gonad weight could reflect direct effects of temperature on physiological rates, or effects of oceanographic conditions on cod distribution and food availability. A positive effect of water temperature anomaly and a negative effect of CIL area on reproductive investment seem reasonable for populations living near the cold end of the species' range (Kjesbu et al. 1998; Yoneda and Wright 2005; Wright et al. 2011). Moreover, Pinhorn (1984) proposed the influence of the water temperature as a potential cause of differences in fecundity observed among the stocks considered 
here. However, in Subdivision 3Ps, CIL area has a positive effect on the gonadal investment of females, which suggests a different mechanism linking oceanographic conditions and reproductive investment. For example, Hutchings and Myers (1994) found a positive effect of cold water on spawning time and attributed this to cold on-shelf conditions in the area forcing the fish to stay in deeper warmer waters. Water temperature anomaly and CIL area do not have a large influence on our results. Importantly, disregarding these variables does not affect the significance of the trends reported in this study except for females in Subdivision 3Ps, where a significant negative trend in gonad weight appears for the full time span. In this sense, the consideration and potential inclusion of temperature effects in our models is conservative.

Biomass does not seem to be a key factor influencing gonad weight in the studied cod populations. The biomass index is retained in models for both sexes in Divisions $3 \mathrm{NO}$ and for females only in Subdivision 3Ps; when present, its influence on gonad weight is consistently negative. A negative effect of population density on fecundity has been shown in many fishes (e.g., Kipling and Frost 1969; Healey 1978; Koslow et al. 1995), including the cod stocks studied here (Stares et al. 2007). As a robustness check, we have confirmed that the choice between considering the stock biomass either in the sampling year or in the previous year (when cod start to divert energy to the maturation of gametes to be released during the next spawning event) does not modify our conclusions about time trends, except for males in Divisions 3NO, where the latter choice suppresses the linear trend.

Of course, a stock biomass index is only a proxy for the per capita availability of resources and does not capture changes originating from the overall availability of resources. For example, the population size and availability of capelin are known to be important for the growth and reproduction of northern cod (Rose and O'Driscoll 2002), but quantifying this interaction over long time periods would be challenging. Nevertheless, because the influence of stock biomass on fecundity-or, in our study, gonad weight-is mediated through the nutritional status of individuals, we may expect this influence to be stronger when the energetic condition of individuals (e.g., through the relative liver index) is not accounted for. In agreement with this expectation, the effect of biomass on gonad weight becomes significant in one case (females in Division $3 \mathrm{~L}$ ) when the relative liver index is excluded from the model. In some other cases, however, the biomass effects on gonad weight remain significant even when the relative liver index is included, which is indicative of a more complex link between stock biomass and gonad weight.

Even though some interannual variability has been reported in the spawning time of cod (Hutchings and Myers 1994; Morgan et al. 2013), this variability seems to be captured by the various individual characteristics (e.g., relative liver index) or sampling characteristics (e.g., longitude) we have considered. As a consequence, the interaction between sampling day and CIL area or water temperature anomaly appears not to bring any additional information, and hence, has never been retained in any of the 12 best models.

\section{Interpretation of temporal trends in gonad weight}

Our results reveal positive residual long-term trends in the gonadal investment of male cod in each of the three populations after the effects of individual, sampling-related, and environmental explanatory variables have been accounted for. Although we cannot rule out the possibility of unaccounted variables acting on phenotypic plasticity, the positive trends observed in males at least during the first halves of the time series are in accordance with the hypothesis that the period of heavy fishing has driven the evolution of higher reproductive investment.

A traditional assessment of the reproductive biology of cod suggests that males should be less likely to show evolutionary responses in gonadal investment than females. In a fish species like cod, featuring 
female mate choice (Hutchings et al. 1999; Nordeide and Folstad 2000; Rowe et al. 2007), male reproductive success should depend less strongly on the number of produced gametes than female reproductive success. In other words, the importance of gonad weight in the determination of fitness is expected to be lower for males than for females. In support of this rationale, Rakitin et al. (2001) did not find a significant relationship between reproductive success and the weight loss of male cod during spawning under experimental conditions. However, GSI values are similar between the two sexes (Fig. 4; Burton et al. 1997), suggesting that an investment in large gonads is also important for male cod. Indeed, the production of higher numbers of spermatozoa can confer an advantage, as male cod mate with several females over the course of a spawning season (Hutchings et al. 1999; Bekkevold et al. 2002). Given that cod sperm remains viable for long periods in water, this may allow male cod to fertilize unfertilized eggs from other mating pairs (Trippel and Morgan 1994).

Our analyses have provided no support for the hypothesis that increased mortality rates have caused the evolution of increased gonadal investment in female cod. However, there are several reasons why an actual evolutionary change might not be detected by our analyses, i.e., why they might be prone to false negatives (type-II errors). First, our methodology is conservative, in that we tested for the significance of the effect of sampling year only after all other significant covariates had been accounted for; specifically, we used a likelihood-ratio test to evaluate whether the inclusion of sampling year could improve a model in which several other significant explanatory variables were already present.

A second explanation for the absence of evidence for an evolutionary increase in female gonadal investment stems from the massive plasticity associated with this metric in cod, as already shown by McIntyre and Hutchings (2003). Naturally, the high variability in gonad weight leads to a reduced statistical power of the analyses. We have tried to minimize this problem by focusing on a single maturity stage for females. Oocytes go through significant changes that influence egg diameter during the late maturity stages (Kjesbu et al. 1990; Kjesbu 1991), and the incorporation of proteins into the oocytes during these stages leads to an increase in gonad weight (Eliassen and Vahl 1982). GSI is not static in males either, but even though male GSI displays a strong increase in the course of spermatogenesis (Dahle et al. 2003), the production of spermatozoa takes place several months prior to spawning (Burton et al. 1997; Rideout and Burton 2000), leading to the relative stability of male GSI values during the maturity stage considered here (Almeida et al. 2008). Indeed, our models for females explain a systematically lower portion of deviance and have higher standard errors for estimates of the effect of sampling year than our models for males. Nevertheless, the point estimates for linear time trends are consistently negative for females (Table 1), suggesting that the absence of positive trends is genuine, rather than representing false negatives (type-II errors).

The prediction that fishing favors increased reproductive investment is qualitatively well established. Only recently, however, have quantitative predictions from eco-genetic models, parameterized for female life histories in cod-like species, shown that fisheries-induced selection not only favors increased GSI, but also that the resultant GSI evolution is slow relative to maturation evolution (Dunlop et al. 2009; Enberg et al. 2009; but see Andersen and Brander 2009, who reached divergent conclusions). It is, therefore, possible that the time period during which two indispensable conditions hold jointly in the three studied populations - that we have adequate quantitative observations and that fisheries-induced selection was strong-has been too short (up to 20 years, and less for analyses including stock biomass) to cause detectable evolutionary change. Moreover, since the exploitation of the studied cod populations had already intensified in the 1950s (Lilly et al. 2008), it is possible that adaptations to high mortality rates occurred before the time period covered in this study. Yet, we argue that adaptation to fishing is unlikely to have halted just a few decades after the industrialization of the Newfoundland cod fishery. 
Our results show that changes in gonadal investment in males have leveled off or reversed in all studied stocks toward the end of the study period. This is in agreement with the prediction that a reduction in total mortality should reverse the evolution of reproductive investment, albeit at a slower pace (Dunlop et al. 2009; Enberg et al. 2009). Such a reversal in gonadal investment should become apparent only with a delay of several years, because it becomes expressed first when the progeny of selected parents reach maturity. The reported negative trends in the gonadal investment of females could also represent such an evolutionary reversal. However, these potential reversals should be interpreted with caution, as their degree is difficult to predict for the stocks studied here, for at least two reasons. First, even after the directed cod fisheries were closed, natural mortality may have remained high (Shelton et al. 2006; Lilly et al. 2013), and selection for increased reproductive investment may, thus, have persisted, albeit at reduced intensity. Second, some cod fishing has taken place during the moratoria in all stocks, and the moratorium for St. Pierre Bank stock was lifted in 1997 (DFO 2015).

In summary, the results of the analyses performed here show evidence for an evolutionary change in gonadal investment for cod populations off Newfoundland, but only for male cod. This suggests that gonad weight has greater importance for the reproductive success of male cod than has previously been acknowledged. The lack of a similar response in female cod could be explained by the relatively short time span with strong fisheries selection, in conjunction with the higher phenotypic variability in gonadal investment in females compared with males; but this does not explain why the available evidence points to negative trends in females, if any. Our findings highlight that investigating the ecological and evolutionary determinants of reproductive investment in wild fish is not straightforward, and underscore how little we know about the reproduction of wild cod in particular, thus calling for more studies unraveling the reproductive biology of this important species.

\section{Acknowledgements}

We thank the many scientific and ship staff involved in the collection of the data used in this study, as well as Christian Jørgensen, Tom Van Dooren, Peter Wright, and anonymous reviewers for helpful comments on earlier versions of this manuscript. This study has been performed with financial support from the European Commission, as part of the Marie Curie Research Training Network FishACE (MRTN-CT-2004-005578) and the Specific Targeted Research Project FinE (SSP-2006-044276) under the European Community's Sixth Framework Program. We also acknowledge support from the Bergen Research Foundation (LB, MH) and the Norwegian Research Council (214189). UD acknowledges funding from the European Science Foundation, the Austrian Science Fund, the Austrian Ministry of Science and Research, and the Vienna Science and Technology Fund. MH acknowledges funding from the Ministry of Science and Technology (MOST), R.O.C., grant number 105-2811-M-002-068.

\section{Author contributions}

LB, MJM, UD, and MH conceived and designed the study. MJM and GRL performed the experiments/collected the data. LB, MJM, and MH analyzed and interpreted the data. MJM and GRL contributed resources. LB, MJM, GRL, UD, and MH drafted or revised the manuscript.

\section{Competing interests}

The authors have declared that no competing interests exist.

\section{Data accessibility statement}

All relevant data are within the paper. 


\section{References}

Almeida FFL, Kristoffersen C, Taranger GL, and Schulz RW. 2008. Spermatogenesis in Atlantic cod (Gadus morhua): a novel model of cystic germ cell development. Biology of Reproduction, 78(1): 27-34. PMID: 17881768 DOI: 10.1095/biolreprod.107.063669

Andersen KH, and Brander K. 2009. Expected rate of fisheries-induced evolution is slow. Proceedings of the National Academy of Sciences of the United States of America, 106(28): 11657-11660. PMID: 19564596 DOI: 10.1073/pnas.0901690106

Audzijonyte A, Kuparinen A, and Fulton EA. 2013. How fast is fisheries-induced evolution? Quantitative analysis of modelling and empirical studies. Evolutionary Applications, 6(4): 585-595. PMID: 23789026 DOI: 10.1111/eva.12044

Bekkevold D, Hansen MM, and Loeschcke V. 2002. Male reproductive competition in spawning aggregations of cod (Gadus morhua, L.). Molecular Ecology, 11(1): 91-102. PMID: 11903907 DOI: $10.1046 / \mathrm{j} .0962-1083.2001 .01424 . \mathrm{x}$

Bell G. 1980. The costs of reproduction and their consequences. The American Naturalist, 116: 45-76. DOI: $10.1086 / 283611$

Bishop CA, Murphy EF, Davis MB, Baird JW, and Rose GA. 1993. An assessment of the cod stock in NAFO divisions 2J+3KL. NAFO Scientific Council Research Document 93/86. Northwest Atlantic Fisheries Organization, Dartmouth, Nova Scotia. 51 p.

Brattey J, Cadigan NG, Healey BP, Lilly GR, Murphy EF, Shelton PA, Stansbury DE, Morgan MJ, and Mahé J-C. 2001. An assessment of the cod stock in NAFO Subdiv. 3Ps in October 2001. DFO Canadian Science Advisory Secretariat Research Document 2001/099, DFO, Ottawa, Ontario. 77 p.

Burton MPM, Penney RM, and Biddiscombe S. 1997. Time course of gametogenesis in Northwest Atlantic cod (Gadus morhua). Canadian Journal of Fisheries and Aquatic Sciences, 54(Suppl. 1): 122-131. DOI: 10.1139/f96-167

Canadian Council on Animal Care. 2005. Guidelines on: the care and use of fish in research, teaching and testing [online]: Available from ccac.ca/Documents/Standards/Guidelines/Fish.pdf.

Dahle R, Taranger GL, Karlsen O, Kjesbu OS, and Norberg B. 2003. Gonadal development and associated changes in liver size and sexual steroids during the reproductive cycle of captive male and female Atlantic cod (Gadus morhua L.). Comparative Biochemistry and Physiology Part A: Molecular \& Integrative Physiology, 136(3): 641-653. DOI: 10.1016/S1095-6433(03)00215-0

Devine JA, Wright PJ, Pardoe H, and Heino M. 2012. Comparing rates of contemporary evolution in life-history traits for exploited fish stocks. Canadian Journal of Fisheries and Aquatic Sciences, 69(6): 1105-1120. DOI: 10.1139/f2012-047

DFO. 2008. 2007 State of the ocean: physical oceanographic conditions in the Newfoundland and Labrador region. DFO Canadian Science Advisory Secretariat Science Advisory Report 2008/017, DFO, Ottawa, Ontario. 11 p.

DFO. 2014. Northern (2J3KL) cod stock update. DFO Canadian Science Advisory Secretariat Science Response 2014/030, DFO, Ottawa, Ontario. 11p. 
DFO. 2015. Stock Assessment of NAFO subdivision 3Ps cod. DFO Canadian Science Advisory Secretariat Science Advisory Report 2015/001, DFO, Ottawa, Ontario. 18 p.

Dunlop ES, Heino M, and Dieckmann U. 2009. Eco-genetic modeling of contemporary lifehistory evolution. Ecological Applications, 19(7): 1815-1834. PMID: 19831072 DOI: 10.1890/ 08-1404.1

Eliassen JE, and Vahl O. 1982. Seasonal variations in biochemical composition and energy content of liver, gonad and muscle of mature and immature cod, Gadus morhua (L.) from Balsfjorden, northern Norway. Journal of Fish Biology, 20(6): 707-716. DOI: 10.1111/j.1095-8649.1982.tb03981.x

Enberg K, Jørgensen C, Dunlop ES, Heino M, and Dieckmann U. 2009. Implications of fisheriesinduced evolution for stock rebuilding and recovery. Evolutionary Applications, 2(3): 394-414. PMID: 25567888 DOI: 10.1111/j.1752-4571.2009.00077.x

Festa-Bianchet M. 2003. Exploitative wildlife management as a selective pressure for the life-history evolution of large mammals. In Animal behavior and wildlife conservation. Edited by FestaBianchet M and Apollonio M. Island Press, Washington, DC, pp. 191-207.

Gunderson DR. 1997. Trade-off between reproductive effort and adult survival in oviparous and viviparous fishes. Canadian Journal of Fisheries and Aquatic Sciences, 54(5): 990-998. DOI: 10.1139/f97-019

Healey MC. 1978. Fecundity changes in exploited populations of lake whitefish (Coregonus clupeaformis) and lake trout (Salvelinus namaycush). Journal of the Fisheries Research Board of Canada, 35(7): 945-950. DOI: 10.1139/f78-155

Heino M, and Kaitala V. 1999. Evolution of resource allocation between growth and reproduction in animals with indeterminate growth. Journal of Evolutionary Biology, 12(3): 423-429. DOI: 10.1046/j. 1420-9101.1999.00044.x

Heino M, Baulier L, Boukal DS, Ernande B, Johnston FD, Mollet FM, et al. 2013. Can fisheriesinduced evolution shift reference points for fisheries management? ICES Journal of Marine Science, 70(4): 707-721. DOI: 10.1093/icesjms/fst077

Heino M, Diaz Pauli B, and Dieckmann U. 2015. Fisheries-induced evolution. Annual Review of Ecology, Evolution, and Systematics, 46: 461-480. DOI: 10.1146/annurev-ecolsys-112414-054339

Hirshfield MF, and Tinkle DW. 1975. Natural selection and the evolution of reproductive effort. Proceedings of the National Academy of Sciences of the United States of America, 72(6): 2227 2231. PMID: 1056027 DOI: 10.1073/pnas.72.6.2227

Hutchings JA, and Myers RA. 1993. Effect of age on the seasonality of maturation and spawning of Atlantic cod, Gadus morhua, in the Northwest Atlantic. Canadian Journal of Fisheries and Aquatic Sciences, 50(11): 2468-2474. DOI: 10.1139/f93-271

Hutchings JA, and Myers RA. 1994. Timing of cod reproduction: interannual variability and the influence of temperature. Marine Ecology Progress Series, 108(1): 21-31. DOI: 10.3354/meps108021

Hutchings JA, Bishop TD, and McGregor-Shaw CR. 1999. Spawning behaviour of Atlantic cod, Gadus morhua: evidence of mate competition and mate choice in a broadcast spawner. Canadian Journal of Fisheries and Aquatic Sciences, 56(1): 97-104. DOI: 10.1139/f98-216 
Jørgensen C, Dunlop ES, Opdal AF, and Fiksen $\emptyset$. 2008. The evolution of spawning migrations: state dependence and fishing-induced changes. Ecology, 89(12): 3436-3448. DOI: 10.1890/07-1469.1

Kipling C, and Frost WE. 1969. Variations in the fecundity of pike Esox lucius L. in Windermere. Journal of Fish Biology, 1(3): 221-237. DOI: 10.1111/j.1095-8649.1969.tb03855.x

Kjesbu OS. 1991. A simple method for determining the maturity stages of Northeast Arctic cod (Gadus morhua L.) by in vitro examination of oocytes. Sarsia, 75(4): 335-338. DOI: 10.1080/ 00364827.1991 .10413458

Kjesbu OS, Witthames PR, Solemdal P, and Greer Walker M. 1990. Ovulatory rhythm and a method to determine the stage of spawning in Atlantic cod (Gadus morhua). Canadian Journal of Fisheries and Aquatic Sciences, 47(6): 1185-1193. DOI: 10.1139/f90-138

Kjesbu OS, Klungsøyr J, Kryvi H, Witthames PR, and Greer Walker M. 1991. Fecundity, atresia, and egg size of captive Atlantic cod (Gadus morhua) in relation to proximate body composition. Canadian Journal of Fisheries and Aquatic Sciences, 48(12): 2333-2343. DOI: 10.1139/f91-274

Kjesbu OS, Witthames PR, Solemdal P, and Greer Walker M. 1998. Temporal variations in the fecundity of Arcto-Norwegian cod (Gadus morhua) in response to natural changes in food and temperature. Journal of Sea Research, 40(3): 303-321. DOI: 10.1016/S1385-1101(98)00029-X

Koslow JA, Bell J, Virtue P, and Smith DC. 1995. Fecundity and its variability in orange roughy: effects of population density, condition, egg size, and senescence. Journal of Fish Biology, 47(6): 1063-1080. DOI: 10.1111/j.1095-8649.1995.tb06030.x

Kunz TH, and Orrell KS. 2004. Energy costs of reproduction. In Encyclopedia of energy. Edited by CJ Cleveland. Elsevier, New York, New York, pp. 423-442.

Lambert Y, and Dutil J-D. 1997. Can simple condition indices be used to monitor and quantify seasonal changes in the energy reserves of cod (Gadus morhua). Canadian Journal of Fisheries and Aquatic Sciences, 54(Suppl. 1): 104-112. DOI: 10.1139/f96-149

Law R. 2000. Fishing, selection, and phenotypic evolution. ICES Journal of Marine Science, 57(3): 659-668. DOI: 10.1006/jmsc.2000.0731

Law R, and Grey DR. 1989. Evolution of yields from populations with age-specific cropping. Evolutionary Ecology, 3(4): 343-359. DOI: 10.1007/BF02285264

Lawson GL, and Rose GA. 2000. Small-scale spatial and temporal patterns in spawning of Atlantic cod (Gadus morhua) in coastal Newfoundland waters. Canadian Journal of Fisheries and Aquatic Sciences, 57(5): 1011-1024. DOI: 10.1139/f00-026

Lilly GR, Wieland K, Rothschild BJ, Sundby S, Drinkwater K, Brander K, et al. 2008. Decline and recovery of Atlantic cod (Gadus morhua) stocks throughout the North Atlantic. In Resiliency of Gadid Stocks to Fishing and Climate Change. Edited by GH Kruse, K Drinkwater, JN Ianelli, JS Link, DL Stram, V Wespestad, and D Woodby. Alaska Sea Grant College Program, Fairbanks, Alaska, pp. 39-66. DOI: 10.4027/rgsfcc.2008.03

Lilly GR, Nakken O, and Brattey J. 2013. A review of the contributions of fisheries and climate variability to contrasting dynamics in two Arcto-boreal Atlantic cod (Gadus morhua) stocks: persistent high productivity in the Barents Sea and collapse on the Newfoundland and Labrador Shelf. Progress in Oceanography, 114: 106-125. DOI: 10.1016/j.pocean.2013.05.008 
McIntyre TM, and Hutchings JA. 2003. Small-scale temporal and spatial variation in Atlantic cod (Gadus morhua) life history. Canadian Journal of Fisheries and Aquatic Sciences, 60(9): 1111-1121. DOI: $10.1139 / \mathrm{f03}-090$

Mertz G, and Myers RA. 1998. A simplified formulation for fish production. Journal of Fisheries and Aquatic Sciences, 55(2): 478-484. DOI: 10.1139/f97-216

Morgan MJ, and Trippel EA. 1996. Skewed sex ratios in spawning shoals of Atlantic cod (Gadus morhua). ICES Journal of Marine Science, 53(5): 820-826. DOI: 10.1006/jmsc.1996.0103

Morgan MJ, Wright PJ, and Rideout RM. 2013. Effect of age and temperature on spawning time in two gadoid species. Fisheries Research, 138: 42-51. DOI: 10.1016/j.fishres.2012.02.019

Nordeide JT, and Folstad I. 2000. Is cod lekking or a promiscuous group spawner? Fish and Fisheries, 1(1): 90-93. DOI: 10.1046/j.1467-2979.2000.00005.x

Olsen EM, Heino M, Lilly GR, Morgan MJ, Brattey J, Ernande B, and Dieckmann U. 2004. Maturation trends indicative of rapid evolution preceded the collapse of northern cod. Nature, 428(6986): 932-935. PMID: 15118724 DOI: 10.1038/nature02430

Olsen EM, Lilly GR, Heino M, Morgan MJ, Brattey J, and Dieckmann U. 2005. Assessing changes in age and size at maturation in collapsing populations of Atlantic cod (Gadus morhua). Canadian Journal of Fisheries and Aquatic Sciences, 62(4): 811-823. DOI: 10.1139/f05-065

Petrie B, Loder JW, Akenhead SA, and Lazier J. 1991. Temperature and salinity variability on the eastern Newfoundland shelf: the annual harmonic. Atmosphere-Ocean, 29(1): 14-36. DOI: 10.1080/ 07055900.1991 .9649390

Pinhorn AT. 1984. Temporal and spatial variation in fecundity of Atlantic cod (Gadus morhua) in Newfoundland waters. Journal of Northwest Atlantic Fishery Science, 5(2): 161-170. DOI: 10.2960/ J.v5.a20

Rakitin A, Ferguson MM, and Trippel EA. 2001. Male reproductive success and body size in Atlantic cod Gadus morhua L. Marine Biology, 138(6): 1077-1085. DOI: 10.1007/s002270100551

Reekie EG, and Bazzaz FA. 1992. Cost of reproduction as reduced growth in genotypes of two congeneric species with contrasting life histories. Oecologia, 90(1): 21-26. PMID: 28312266 DOI: $10.1007 /$ BF00317804

Rideout RM, and Burton MPM. 2000. The reproductive cycle of male Atlantic cod (Gadus morhua L.) from Placentia Bay, Newfoundland. Canadian Journal of Zoology, 78(6): 1017-1025. DOI: 10.1139/ z00-006

Rideout RM, Murphy EF, Brattey J, and Power D. 2013. An assessment of the cod stock in NAFO Divisions 3NO. NAFO Scientific Council Research Document 13/044. Northwest Atlantic Fisheries Organization, Dartmouth, Nova Scotia. 47 p.

Rijnsdorp AD. 1993. Fisheries as a large-scale experiment on life-history evolution: disentangling phenotypic and genetic effects in changes in maturation and reproduction of North Sea plaice, Pleuronectes platessa L. Oecologia, 96(3): 391-401. PMID: 28313655 DOI: 10.1007/BF00317510 
Rijnsdorp AD, Grift RE, and Kraak SBM. 2005. Fisheries-induced adaptive change in reproductive investment in North Sea plaice (Pleuronectes platessa)? Canadian Journal of Fisheries and Aquatic Sciences, 62(4): 833-843. DOI: 10.1139/f05-039

Robichaud D, and Rose GA. 2003. Sex differences in cod residency on a spawning ground. Fisheries Research, 60(1): 33-43. DOI: 10.1016/S0165-7836(02)00065-6

Roff DA. 1983. An allocation model of growth and reproduction in fish. Canadian Journal of Fisheries and Aquatic Sciences, 40(9): 1395-1404. DOI: 10.1139/f83-161

Roff DA. 1992. The evolution of life histories: theory and analysis. Chapman \& Hall, London, UK. $535 \mathrm{p}$.

Rose GA, and O'Driscoll RL. 2002. Capelin are good for cod: can the northern stock rebuild without them? ICES Journal of Marine Science, 59(5): 1018-1026. DOI: 10.1006/jmsc.2002.1252

Rowe S, Hutchings JA, and Skjæraasen JE. 2007. Nonrandom mating in a broadcast spawner: mate size influences reproductive success in Atlantic cod (Gadus morhua). Canadian Journal of Fisheries and Aquatic Sciences, 64(2): 219-226. DOI: 10.1139/f06-182

Schielzeth H. 2010. Simple means to improve the interpretability of regression coefficients. Methods in Ecology and Evolution, 1(2): 103-113. DOI: 10.1111/j.2041-210X.2010.00012.x

Sharpe DMT, Wandera SB, and Chapman LJ. 2012. Life history change in response to fishing and an introduced predator in the East African cyprinid Rastrineobola argentea. Evolutionary Applications, 5(7): 677-693. DOI: 10.1111/j.1752-4571.2012.00245.x

Shelton PA, and Morgan MJ. 2005. Is by-catch mortality preventing the rebuilding of cod (Gadus morhua) and American plaice (Hippoglossoides platessoides) stocks on the Grand Bank? Journal of Northwest Atlantic Fishery Science, 36: 1-17. DOI: 10.2960/J.v36.m544

Shelton PA, Sinclair AF, Chouinard GA, Mohn R, and Duplisea DE. 2006. Fishing under low productivity conditions is further delaying recovery of Northwest Atlantic cod (Gadus morhua). Canadian Journal of Fisheries and Aquatic Sciences, 63(2): 235-238. DOI: 10.1139/f05-253

Skjæraasen JE, Nilsen T, and Kjesbu OS. 2006. Timing and determination of potential fecundity in Atlantic cod (Gadus morhua). Canadian Journal of Fisheries and Aquatic Sciences, 63(2): 310-320. DOI: $10.1139 / \mathrm{f0}-218$

Stares JC, Rideout RM, Morgan MJ, and Brattey J. 2007. Did population collapse influence individual fecundity of Northwest Atlantic cod? ICES Journal of Marine Science, 64(7): 1338-1347. DOI: 10.1093/icesjms/fsm127

Stearns SC. 1992. The evolution of life histories. Oxford University Press, New York, New York, 262 p.

Stockley P, Gage MJG, Parker GA, and Møller AP. 1997. Sperm competition in fishes: the evolution of testis size and ejaculate characteristics. The American Naturalist, 149(5): 933-954. PMID: 18811256 DOI: $10.1086 / 286031$

Stoltz JA, Neff BD, and Olden JD. 2005. Allometric growth and sperm competition in fishes. Journal of Fish Biology, 67(2): 470-480. DOI: 10.1111/j.0022-1112.2005.00756.x 
Templeman W, Hodder VM, and Wells R. 1978. Sexual maturity and spawning in haddock, Melanogrammus aeglefinus, of the southern Grand Bank. ICNAF Research Bulletin, 13: 53-65.

Thomas G, Quoß H, Hartmann J, and Eckmann R. 2009. Human-induced changes in the reproductive traits of Lake Constance common whitefish (Coregonus lavaretus). Journal of Evolutionary Biology, 22(1): 88-96. PMID: 19127609 DOI: 10.1111/j.1420-9101.2008.01622.x

Tomkiewicz J, Morgan MJ, Burnett J, and Saborido-Rey F. 2003. Available information for estimating reproductive potential of Northwest Atlantic groundfish stocks. Journal of Northwest Atlantic Fishery Science, 33: 1-21. DOI: 10.2960/J.v33.a1

Tomkins JL, and Simmons LW. 2002. Measuring relative investment: a case study of testes investment in species with alternative male reproductive tactics. Animal Behaviour, 63: 1009-1016. DOI: 10.1006/ anbe.2001.1994

Trippel EA, and Morgan MJ. 1994. Sperm longevity in Atlantic cod (Gadus morhua). Copeia, 1994, 1994: 1025-1029. DOI: $10.2307 / 1446727$

Vøllestad LA, and L'Abée-Lund JH. 1994. Evolution of the life history of Arctic charr Salvelinus alpinus. Evolutionary Ecology, 8: 315-327. DOI: 10.1007/BF01238281

Williams GC. 1966. Natural selection, the costs of reproduction, and a refinement of Lack's principle. The American Naturalist, 100(916): 687-690. DOI: 10.1086/282461

Wright PJ, Gibb FM, Gibb IM, and Millar CP. 2011. Reproductive investment in the North Sea haddock: temporal and spatial variation. Marine Ecology Progress Series, 432: 149-160. DOI: $10.3354 /$ meps09168

Yoneda M, and Wright PJ. 2004. Temporal and spatial variation in reproductive investment of Atlantic cod Gadus morhua in the northern North Sea and Scottish west coast. Marine Ecology Progress Series, 276: 237-248. DOI: 10.3354/meps276237

Yoneda M, and Wright PJ. 2005. Effect of temperature and food availability on reproductive investment of first-time spawning male Atlantic cod, Gadus morhua. ICES Journal of Marine Science, 62(7): 1387-1393. DOI: 10.1016/j.icesjms.2005.04.018 